Division of Animal Production,

Veterinary College, AL-Bath University, Syria.

\title{
STUDY OF THE INFLUENCE OF THE INTENSIVE USAGE OF INTRAVAGINAL SPONGES ON THE WEIGHT OF LAMBS OF AWASSI BREED IN SYRIA
} (With 14 Tables)

\author{
By \\ H. AL JASEM and JIHAD MASSOUH
}

(Received at 10/11/2010)

دراسة تأثير الاستخدام المكثف للاسفنجات المهبلية على وزن حملان الاغنام

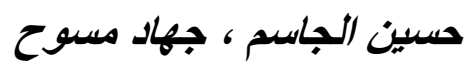

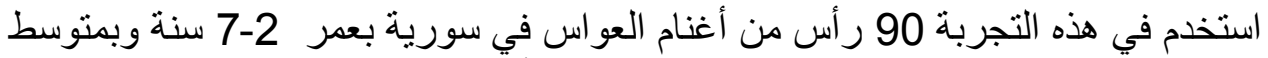

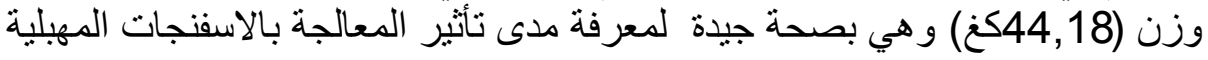

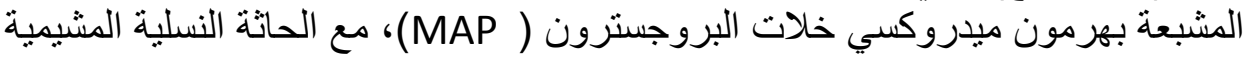

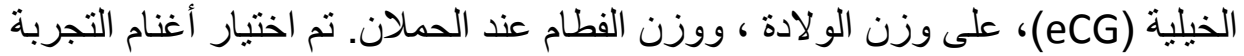

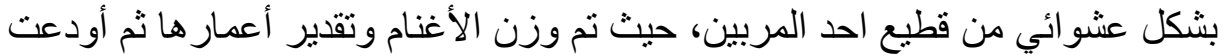

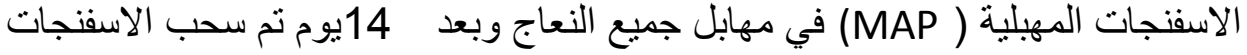

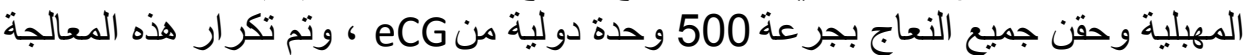

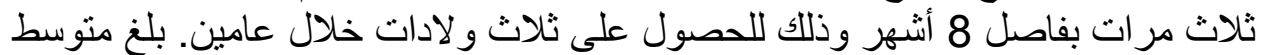

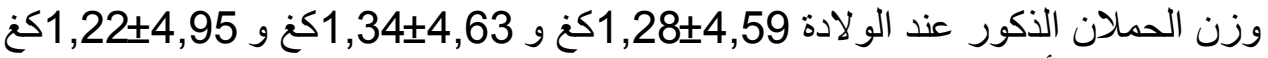

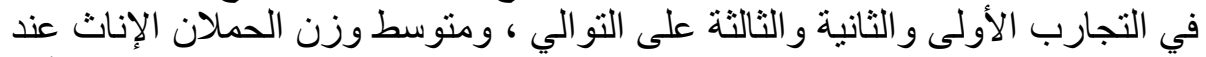

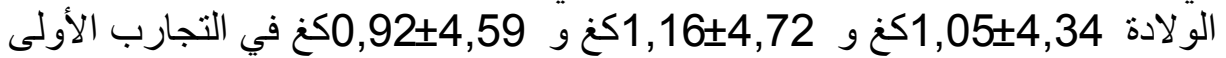

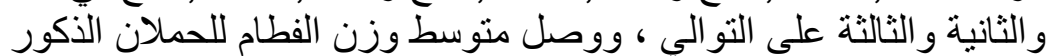

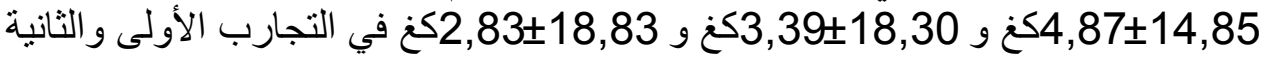

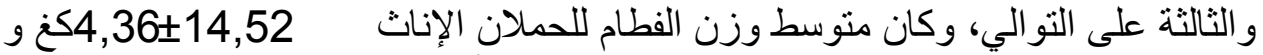

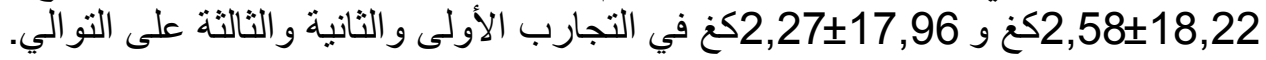

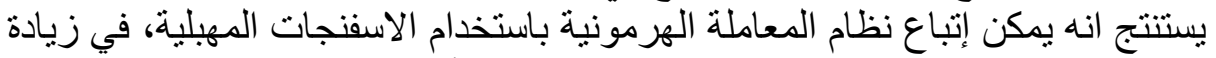

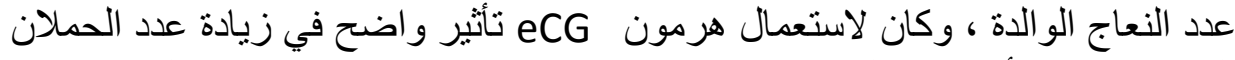
المولودة ، دون أن يؤثر ذلك على متوسط وزن الون لأن لادة و الفطام عند حملان التجربة.

\section{SUMMARY}


90 of Awassi ewes (2-7) years old, $(44,18) \mathrm{Kg}$ weight and in a good health, were used to study the, efficieny of hormonal treatment, by using intravaginal progestagen sponges containing $60 \mathrm{mg}$ of medroxy progesterone acetate (MAP) followed by treatment with equine chorionic gonadotrphin (eCG), birth on weight and weight at weaning. 90 of Awassi ewes were randomly chosen at one of the breeders. That ewes have been weighed and fixed their ages, intravaginally sponges with $60 \mathrm{mg}$ medroxy progesterone acetate, and after 14 days all the ewes were injected intramuscularly with 500IU eCG of ,and the treatment has been repeated for three times in 8 months interval to get three births during two years. It was found, that average weights of the total males at the birth were $4,59 \pm 1,28 \mathrm{~kg}, 4,63 \pm 1,34 \mathrm{~kg}, 4,95 \pm 1,22 \mathrm{~kg}$ in the first, second and third experiment respectively. The aveage weights of total females at the birth were $4,34 \pm 1,05 \mathrm{~kg}, 4,72 \pm 1,16 \mathrm{~kg}, 4,59 \pm 0,92 \mathrm{~kg}$ in the first, second and third experiment respectively, and the aveage weight of males at the weaning $14,85 \pm 4,87 \mathrm{~kg}, 18,30 \pm 3,39 \mathrm{~kg}, 18,83 \pm 2,83 \mathrm{~kg}$, in the first, second and third experiment respectively, the aveage weight of females at the weaning $14,52 \pm 4,36 \mathrm{~kg}, 18,22 \pm 2,58 \mathrm{~kg}, 17,96 \pm 2,27 \mathrm{~kg}$, in the first, second and third experiment respectively. It was concluded that the hormonal treatment could be used for intensification of the sheep production and for increasing the reproductivity of Awassi sheep. The usage of hormonal eCG had clear affecting on increasing the number of born lamb, without effection on the average birth and weaning weight of the lambs.

Key words: Sheep, Awassi ewes, lambs, intravaginal sponges, hormonal treatment

\section{INTRODUCTION}
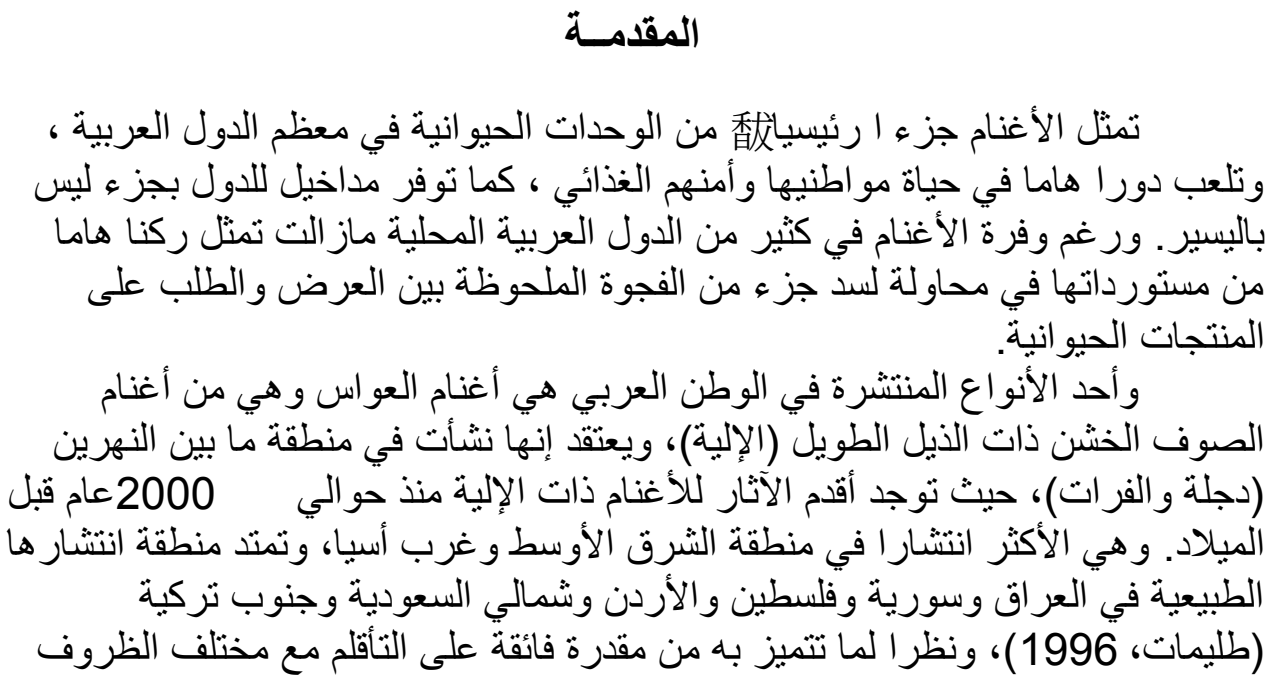


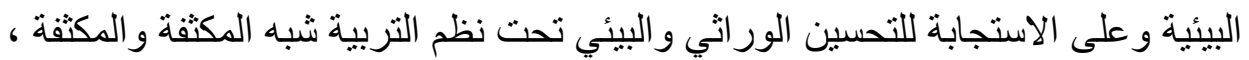

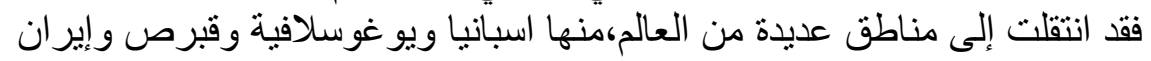

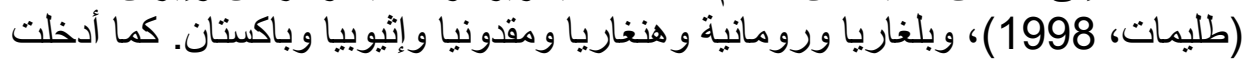

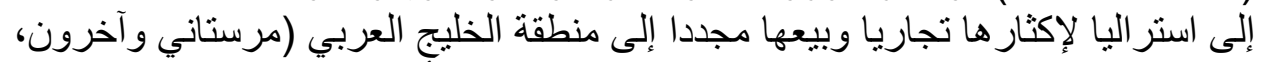

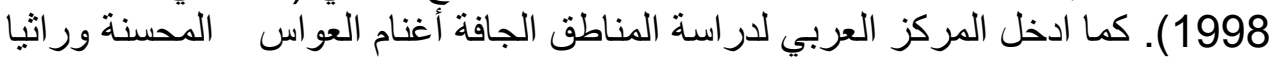

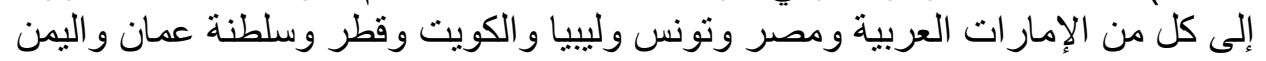
(طليمات و آخرون، الإمارت 2002). وهي العرق الوحيد في وهي سورية ، و وتشكل حوالي

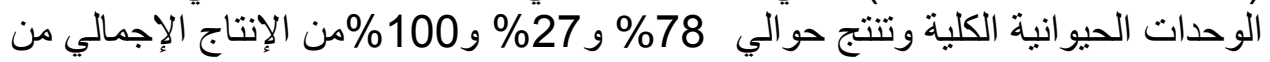

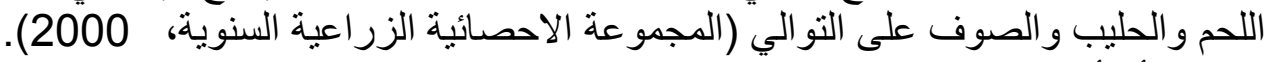

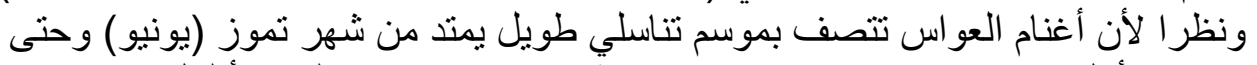

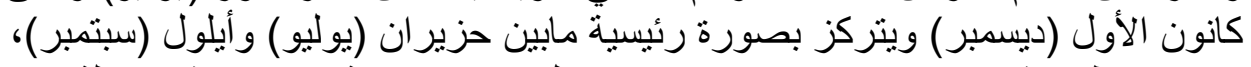

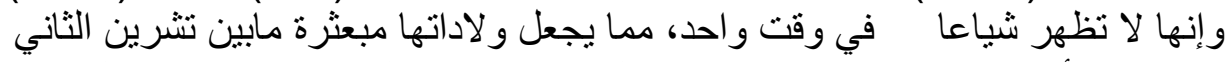

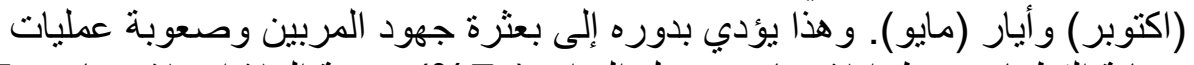

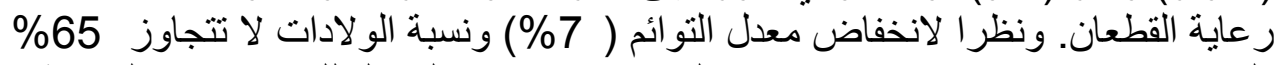

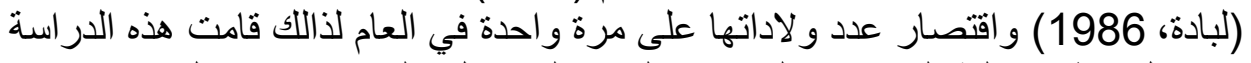

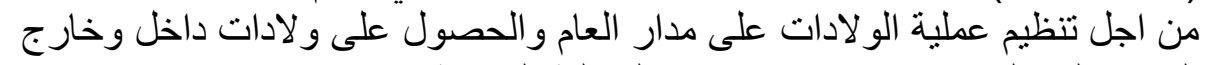

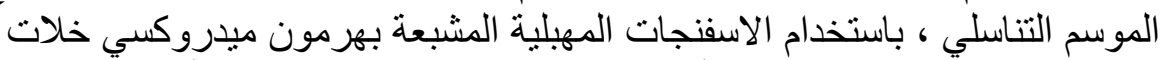

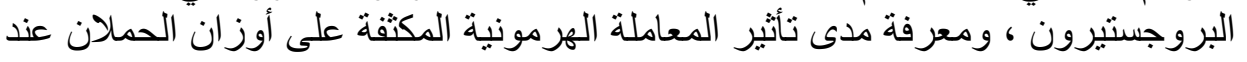

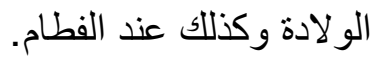

\section{MATERIALS and METHODS مواد البحث وطر ائق العمل}

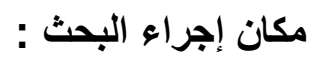

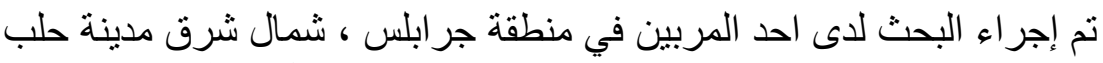

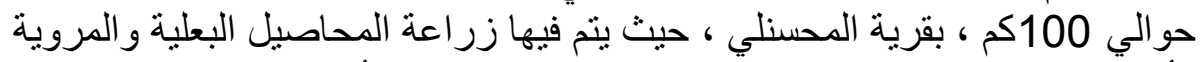

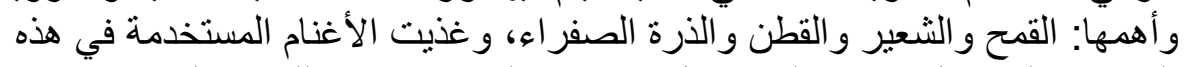
الدر اسة على مخلفات هذه المحاصيل ، والفيل وكانت التربية مشابهة للتربية السرحية.

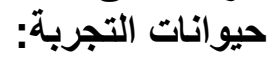

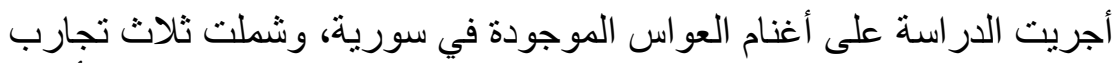

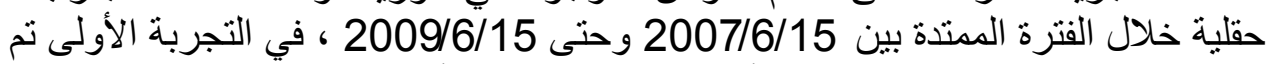

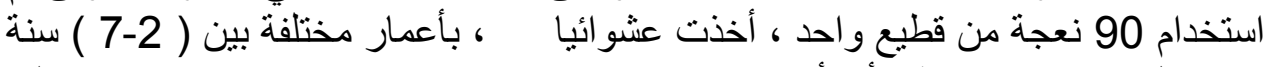

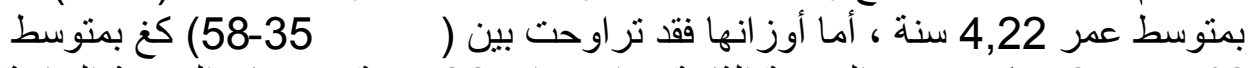

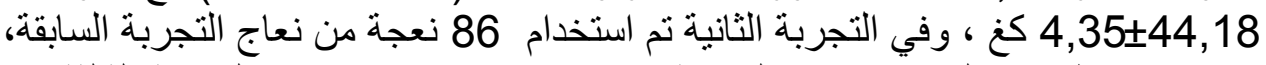
وكان منوسط وزن النعاج في هذه التجربة

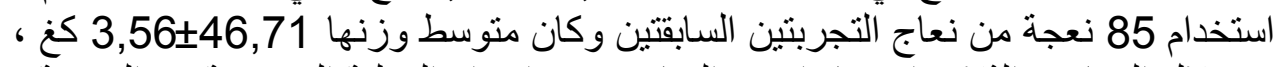

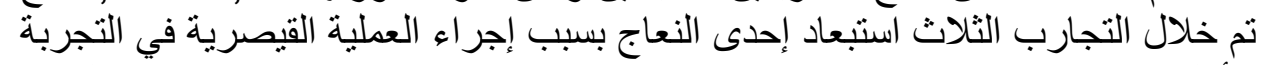

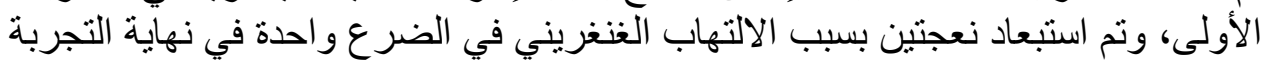


الأولى و الثانية في نهاية التجربة الثانية، وتم النفوق عند نعجنين بسبب الإصابة بالانتروتوكسيميا بين التجربتين الأولى و الثانية.

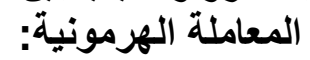

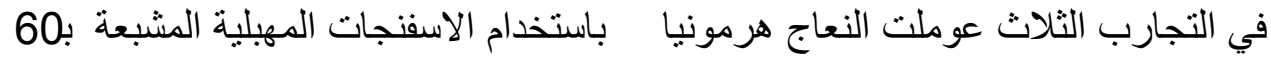

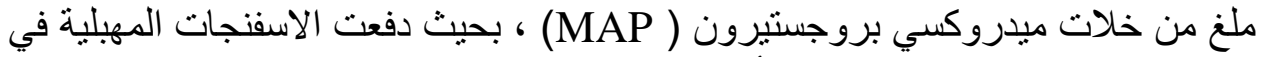

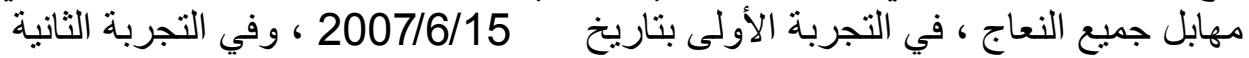

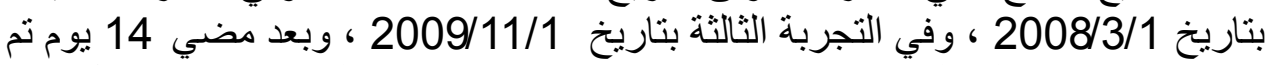

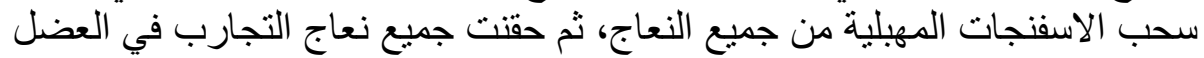

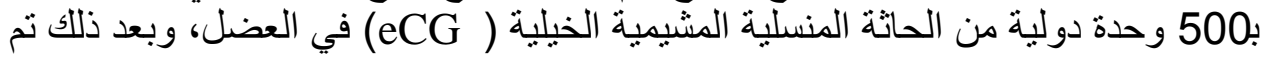

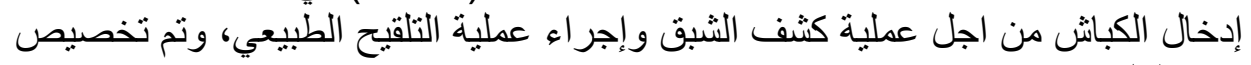
كبش لكل 5 نعاج.

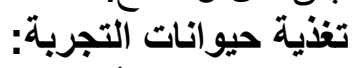

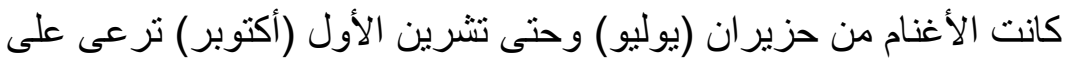

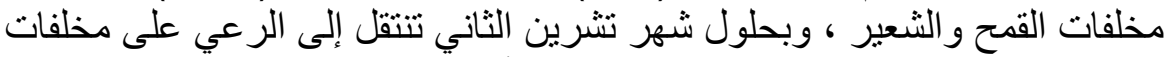

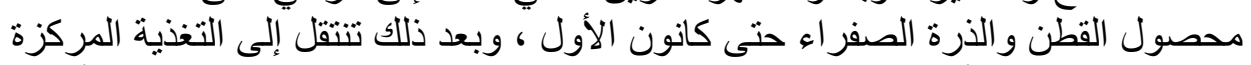

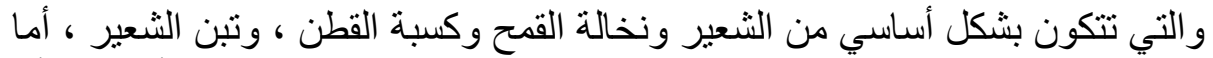

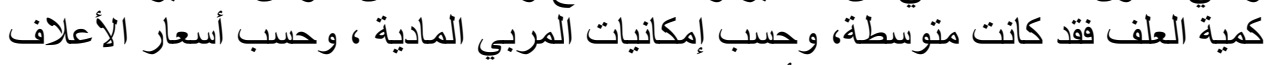

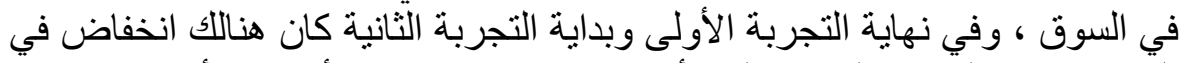

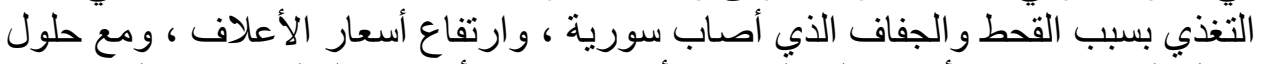

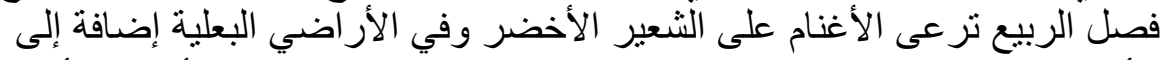

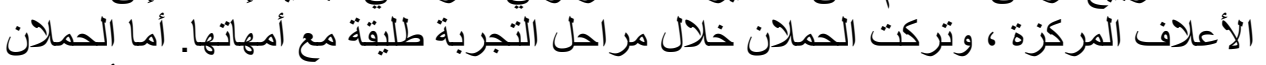

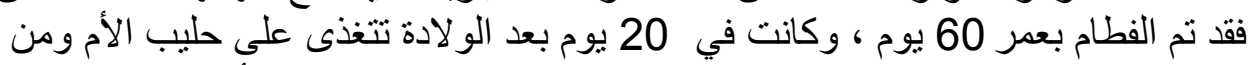

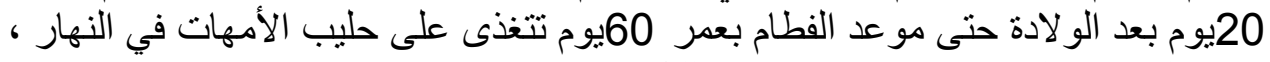
وتبن الشعير والثعير وكسبة القطن في الليل.

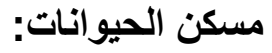

في فصل الثتاء و عند الظروف المناخية السيئة ، توضع الأغنام في حظائر مغلقة

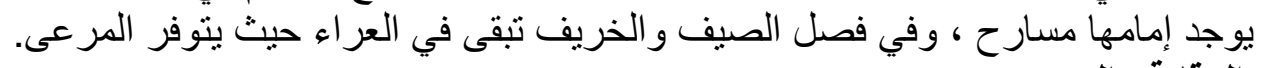
الوقاية و التحصين:

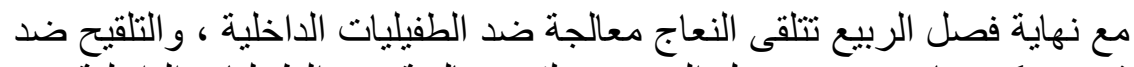

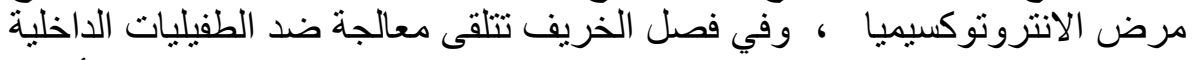

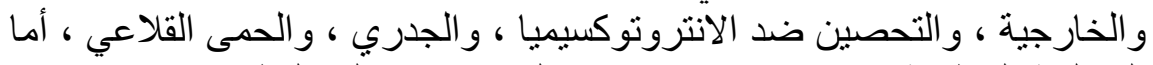

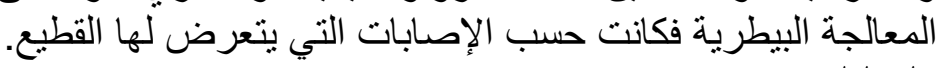
التحليل الإحصائي:

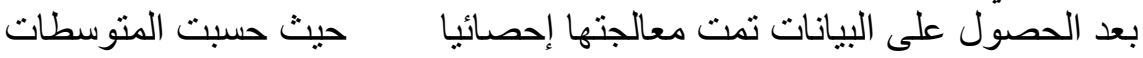

و الانحر اف المعياري ، و استخدام النموذج الإحصائي ذو الاتجاهين (ANOVA).

\section{RESULTS}

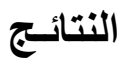


الجدول (1) يبين منوسط أوزان الحملان حسب نوع الولادة في التجربة الأولى الجدول 1: يبين منوسط أوزان الحملان ونوع الو لادة عند نعاج التجربة الأولى

\begin{tabular}{|c|c|c|c|c|c|c|c|}
\hline \multirow[t]{3}{*}{$\mathrm{P}$} & \multicolumn{4}{|c|}{ متوسط أوزان المو اليد تبعا للجنس (كغ) } & \multirow[t]{3}{*}{ 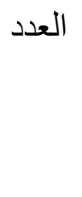 } & \multirow[t]{3}{*}{ 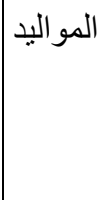 } & \multirow{3}{*}{ النعاج } \\
\hline & \multicolumn{2}{|c|}{ حملان إناث } & \multicolumn{2}{|c|}{ حملان ذكور } & & & \\
\hline & 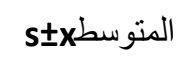 & 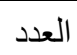 & المتوسط SEx & 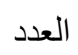 & & & \\
\hline ns & $0,79 \pm 4,97$ & 37 & $1,01 \pm 5,20$ & 19 & 56 & إفرادي & 56 \\
\hline ns & $0,7 \pm 3,50$ & 28 & $1,08 \pm 3,52$ & 10 & 38 & تو أمي & 19 \\
\hline ns & $1,05 \pm 4,34$ & 65 & $1,28 \pm 4,59$ & 29 & 94 & 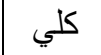 & 57 \\
\hline
\end{tabular}

ns: $(\mathrm{p}>0,05)$

يبين الجدول (1) عدم وجود فرق معنوي في أوزان المو اليد الذكور و الإناث عند

الولادة ، وكان هنالك 56 حملا

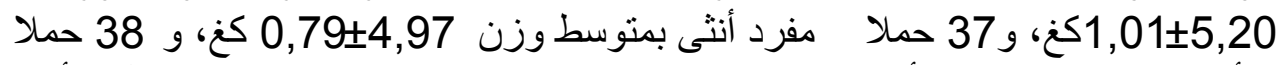

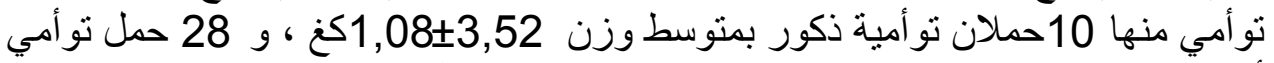

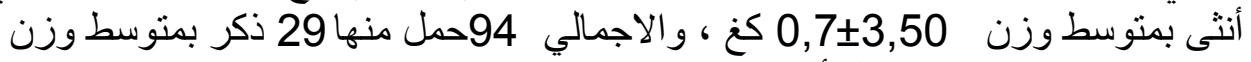

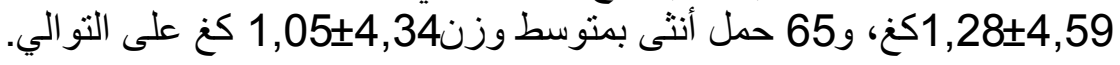

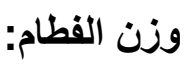

يبين الجدول (2) عدم وجود فرق معنوي بين منوسط أوزان الفطام ، وكان هناللك

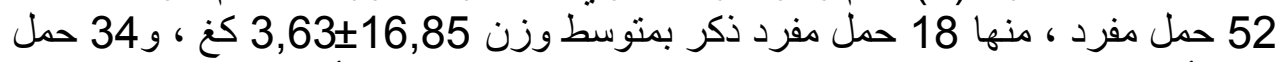

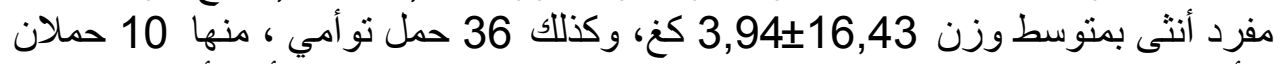

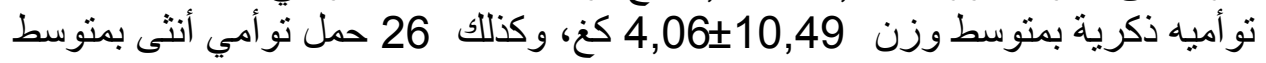

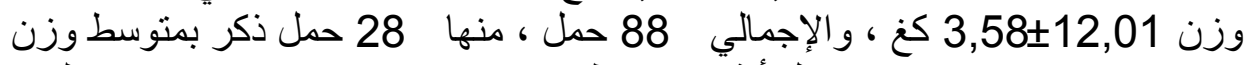

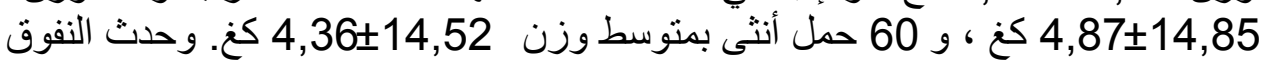
لاى 6 حملان 4 من الو لادة الفردية و 24 الون الو لادة التوامية.

الجدول 2: يبين مقارنة بين أوزان الفطام لحملان التجربة الأولى

\begin{tabular}{|c|c|c|c|c|c|c|c|}
\hline$P$ & \multicolumn{4}{|c|}{ متوسط أوزان الحملان عند الفطام تبعا للجنس (كغ) } & معد & 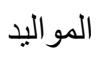 & \multirow{3}{*}{ النعاج } \\
\hline & \multicolumn{2}{|c|}{ حملان إناث } & \multicolumn{2}{|c|}{ حملان ذكور } & & & \\
\hline & SExx المتو سط & العدد & 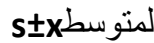 & العدد & & & \\
\hline
\end{tabular}


Assiut Vet. Med. J. Vol. 57 No. 128 January 2011

\begin{tabular}{|c|c|c|c|c|c|c|c|}
\hline $\begin{array}{c}\mathrm{N} \\
\mathrm{s}\end{array}$ & $3,94 \pm 16,43$ & 34 & $3,63 \pm 16,85$ & 18 & 52 & إفرادي & 56 \\
\hline $\begin{array}{c}\mathrm{N} \\
\mathrm{s}\end{array}$ & $3,58 \pm 12,01$ & 26 & $4,06 \pm 10,49$ & 10 & 36 & تو أمي & 19 \\
\hline $\begin{array}{c}\mathrm{N} \\
\mathrm{s}\end{array}$ & $4,36 \pm 14,52$ & 60 & $4,87 \pm 14,85$ & 28 & 88 & كلي & 75 \\
\hline
\end{tabular}

ns: $(p>0,05)$

وزن التجربة الثانية:

الجدول (3) ييين متوسط وزن الو لادة لحملان التجربة الثانية.

الجدول 3: يبين متوسط أوزان الحملان ونوع الو لادة عند نعاج التجربة الثانية

\begin{tabular}{|c|c|c|c|c|c|c|c|}
\hline \multirow[t]{3}{*}{$\mathrm{p}$} & \multicolumn{4}{|c|}{ متوسط أوزان المو اليد تبعا للجنس (كغ) } & \multirow[t]{3}{*}{ 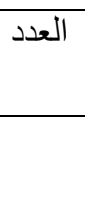 } & \multirow[t]{3}{*}{ المو اليد } & \multirow{3}{*}{ النعاج } \\
\hline & \multicolumn{2}{|c|}{ حملان إناث } & \multicolumn{2}{|c|}{ حملان ذكور } & & & \\
\hline & المتوسطx SEx & 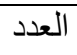 & المتوسطx SEx & 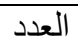 & & & \\
\hline ns & $0,53 \pm 5,36$ & 24 & $0,58 \pm 5,62$ & 30 & 54 & إفرادي & 54 \\
\hline$*$ & $0,15 \pm 2,99$ & 9 & $0,39 \pm 3,30$ & 17 & 26 & تو أمي & 13 \\
\hline 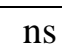 & $1,16 \pm 4,72$ & 33 & $1,34 \pm 4,63$ & 47 & 80 & كلي & 67 \\
\hline
\end{tabular}

ns $:(p>0,05)$

$*:(\mathrm{P}<0.05)$

يبين الجدول رقم ( 3)عدم وجود فرق معنوي بين منوسطوز وزن الحملان الذكور

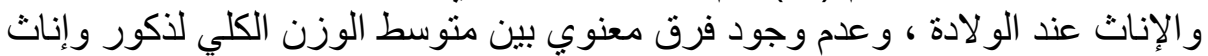

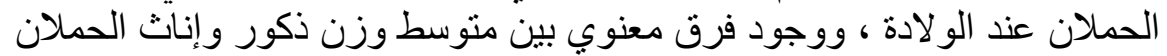

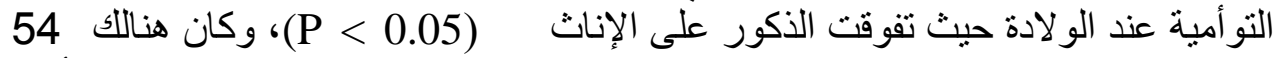

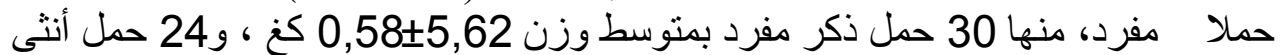

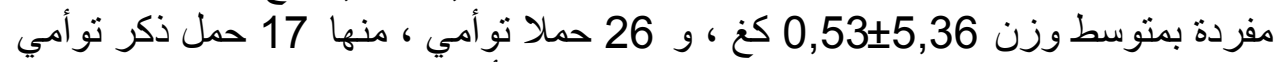

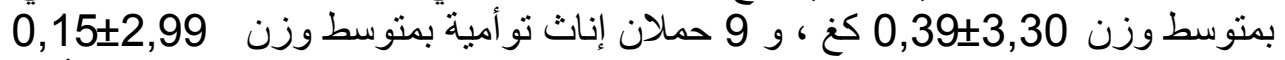

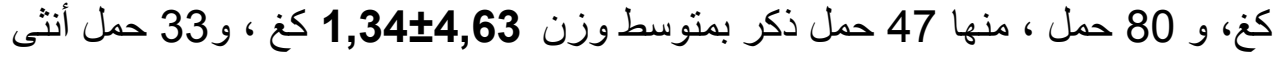

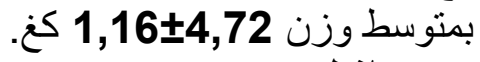

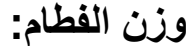

الجدول (4) يبين منوسط وزن الفطام عند حملان التجربة الثانية الجدول 4: يبين مقارنة بين أوزان الفطام لحملان التجربة الثانية

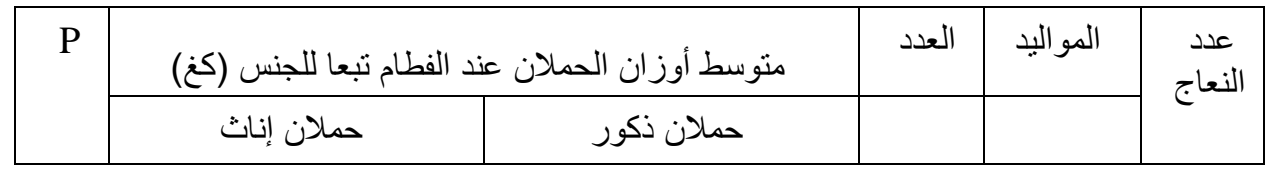




\begin{tabular}{|c|c|c|c|c|c|c|c|}
\hline & المتو سطX & العدد & SEx المتوسط & العدد & & & \\
\hline * & $1,74 \pm 19,45$ & 24 & $1,86 \pm 20,67$ & 30 & 54 & إفر ادي & 54 \\
\hline ns & $1,19 \pm 14,96$ & 9 & $0,89 \pm 15,23$ & 17 & 26 & تو أمي & 13 \\
\hline ns & $2,58 \pm 18,22$ & 33 & $3,39 \pm 18,30$ & 47 & 80 & كلي & 67 \\
\hline
\end{tabular}

ns: $(\mathrm{p}>0,05)$

$$
*:(\mathrm{P}<0.05)
$$

يبين الجدول رقم ( 4 ( عدم وجود فرق معنوي بين متوسط وزن الحملان الذكور

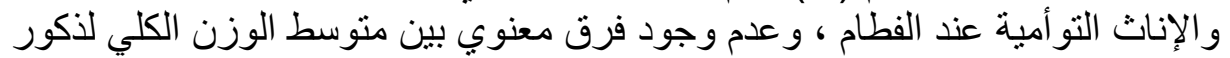

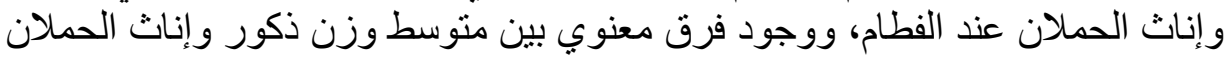

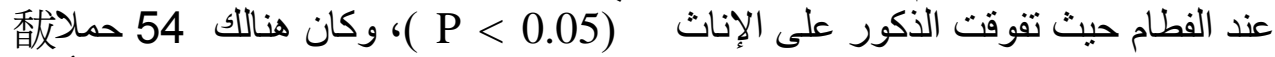

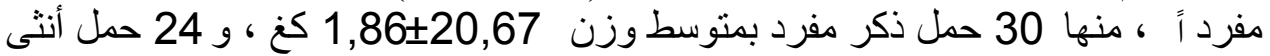

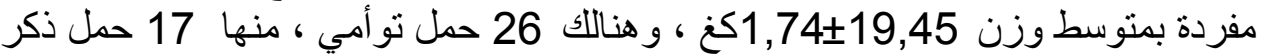

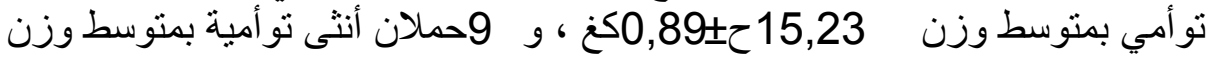

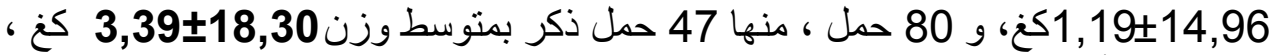

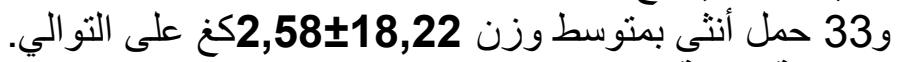

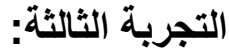

وزن الولادة:

الجدول (5) يبين متوسطات وزن الولادة عند حملان التجربة الثالثة. الجدول 5: يبين متوسط أوز ان الحملان ونوع الولادة عند نعاج التجربة الثالثة

\begin{tabular}{|c|c|c|c|c|c|c|c|}
\hline \multirow[t]{3}{*}{$\mathrm{p}$} & \multicolumn{4}{|c|}{ متوسط أوزان المو اليد تبعا للجنس (كغ) } & \multirow[t]{3}{*}{ العدد } & \multirow[t]{3}{*}{ المو اليد } & \multirow{3}{*}{ لنعاج } \\
\hline & \multicolumn{2}{|c|}{ حملان إناث } & \multicolumn{2}{|c|}{ حملان ذكور } & & & \\
\hline & المتوسطx s_x & العدد & المتوسط\$x_x & العدد & & & \\
\hline$* *$ & $0,38 \pm 5,19$ & 35 & $0,50 \pm 5,81$ & 20 & 55 & إفر ادي & 55 \\
\hline ns & $0,38 \pm 3,43$ & 18 & $2,83 \pm 3,52$ & 12 & 30 & تو أمي & 15 \\
\hline ns & $0,92+4,59$ & 53 & $1,22+4,95$ & 32 & 85 & كلي & 70 \\
\hline
\end{tabular}

$\mathrm{ns}:(\mathrm{p}>0,05)$

$* *:(\mathrm{P}<0.01)$

ويظهر الجدول (5) عدم وجود فرق معنوي بين منوسط وزن الحملان الذكور

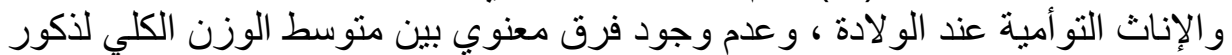

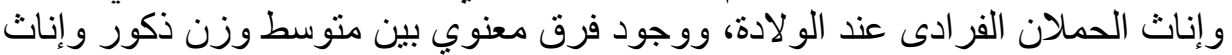
الحملان الفردية عند الولادة حيث تفوقت الذكور على الإناث (P

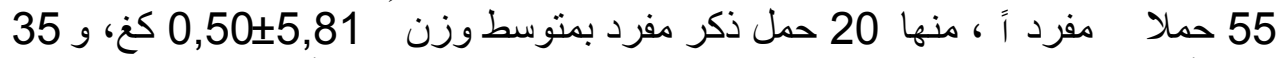

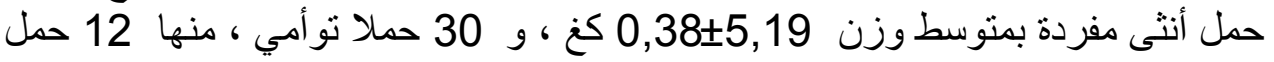




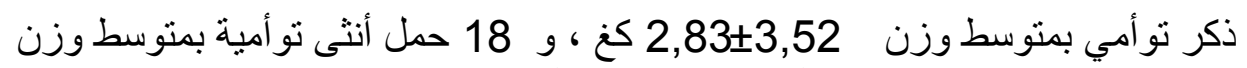

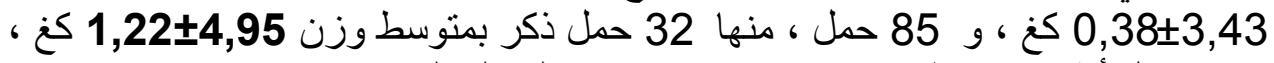

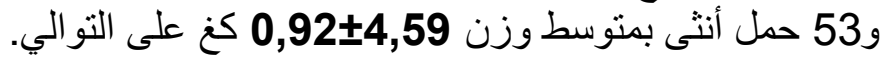
وزن الفطام : وند جمان الجدول (6) يبين متوسط أوزان الفطام عند حملان التجربة الثالثة الجدول 6: يبين مقارنة بين أوزان الفطام لحملان التجربة الثالثة

\begin{tabular}{|c|c|c|c|c|c|c|c|}
\hline \multirow[t]{3}{*}{$\mathrm{P}$} & \multicolumn{4}{|c|}{ متوسط أوزان الحملان عند الفطام تبعا للجنس (كغ) } & \multirow[t]{3}{*}{ العدد } & \multirow[t]{3}{*}{ المو اليد } & \multirow{3}{*}{ النعاج } \\
\hline & \multicolumn{2}{|c|}{ حملان إناث } & \multicolumn{2}{|c|}{ حملان ذكور } & & & \\
\hline & الهتوسطx SE & العدد & المتوسطx_x & العدد & & & \\
\hline$* *$ & $1,52+19,27$ & 35 & $1,56 \pm 20,74$ & 20 & 55 & إفرادي & 55 \\
\hline ns & $0,92+15,43$ & 18 & $0,79 \pm 15,64$ & 12 & 30 & تو أمي & 15 \\
\hline ns & $2,27 \pm 17,96$ & 53 & $2,83 \pm 18,83$ & 32 & 85 & كلى & 70 \\
\hline
\end{tabular}

ns: $(p>0,05)$

$* *:(\mathrm{P}<0.01)$

يبين الجدول ( 6) عدم وجود فرق معنوي بين متوسط وزن الحملان الذكور

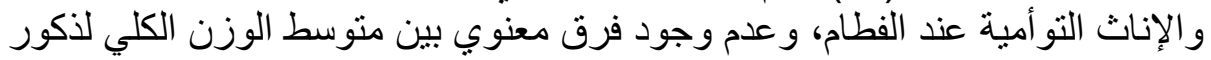

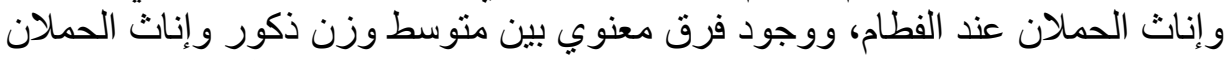

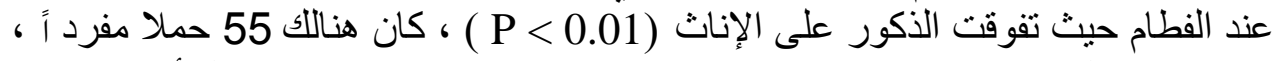

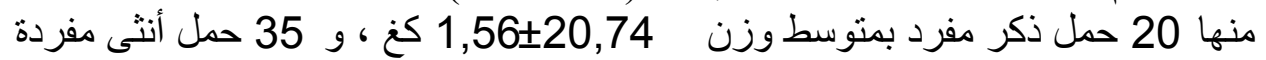

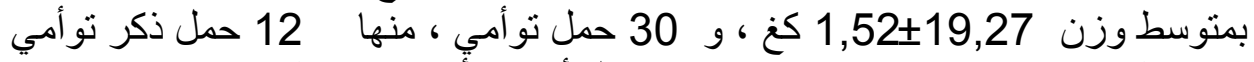

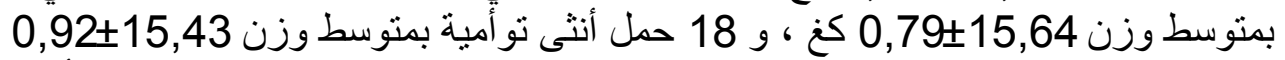

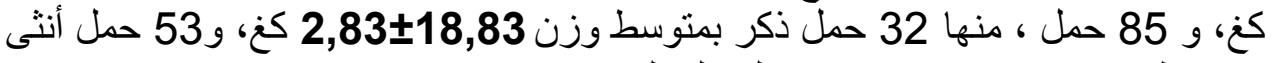

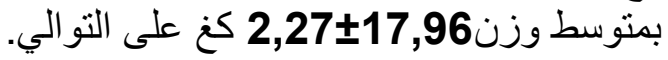

\section{- متوسطات أوزن الولادة للحملان:

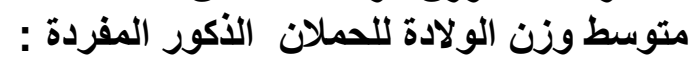
الجدول رقم (7) يبين متوسط وزن الوة لادون لادة للحملان الذكور المفردة في التجارب الثلاث.

جدول رقم 7: منوسطوزن الولادة للحملان الذكور المفردة

\begin{tabular}{|c|c|c|c|}
\hline التجربة الثالثة & التجربة الثانية & التجربة الأولى & البيان \\
\hline${ }^{a} 5,81$ & ${ }^{a} 5,62$ & ${ }^{b} 5,20$ & متوسط وزن المفردة كغ لادة للحملان \\
\hline
\end{tabular}

تشثير الأحرف المتشابهة إلى عدم وجود فرق معنوي: (p > 0,05) 
يبين الجدول (7) إن منوسط الوزن للحملان الذكور الفردية بلغ عند الولادة في

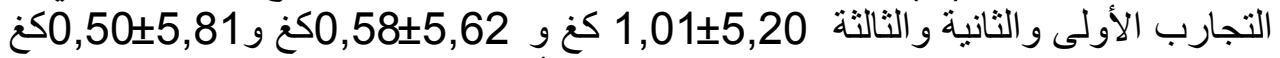

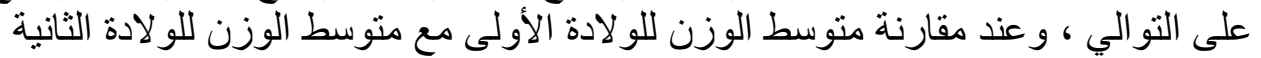

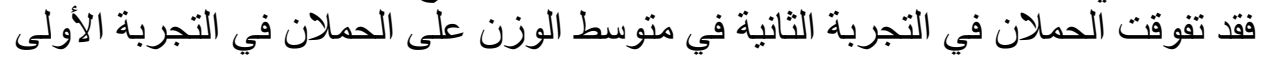

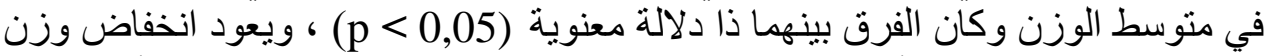

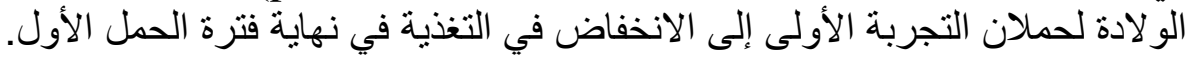

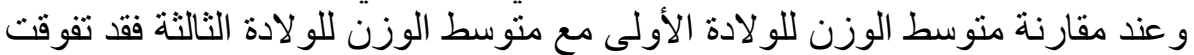

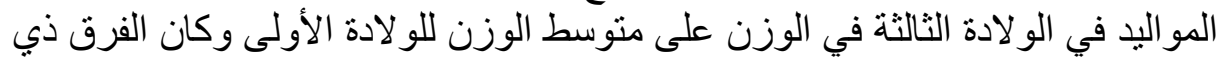

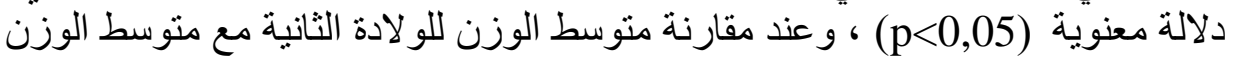

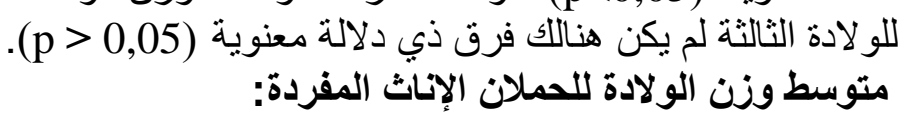

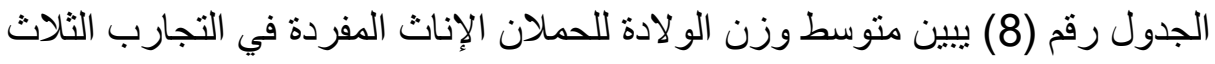

جدول رقم 8: متوسط وزن الولادة للحملان الإناث المفردة في التجارب الثلاث

\begin{tabular}{|c|c|c|c|}
\hline التجربة الثالثة & التجربة الثانية & التجربة الأولى & البيان \\
\hline${ }^{\mathrm{ab}} 5,19$ & a5,36 & ${ }^{\mathrm{b}} 4,97$ & 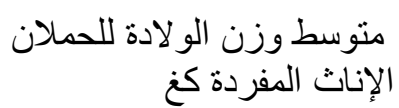 \\
\hline
\end{tabular}

يبين الجدول ( 8) إن متوسط الوزن للحملان الإناث بلغ في التجارب الأولى

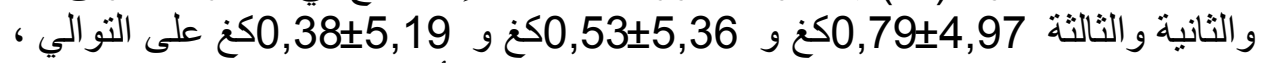

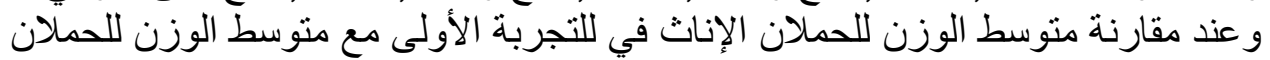

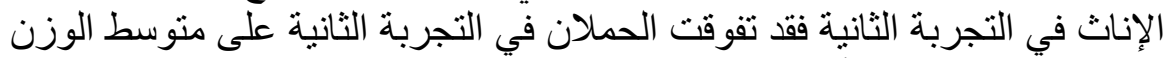

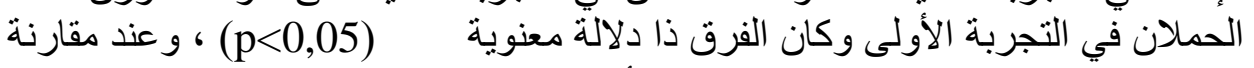

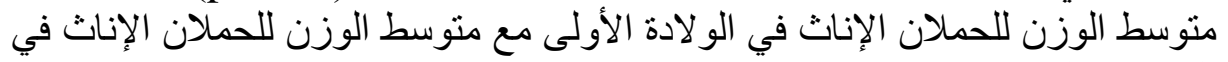

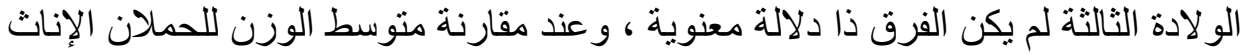

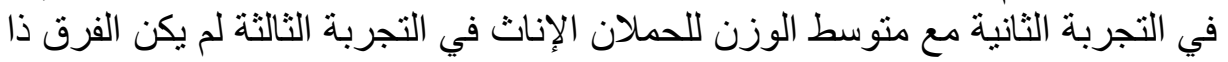

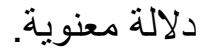

متوسط وزن الولادة للحملان الأكور التوأمية : الجدول رقم (9) ييين منوسط وزن الو لادة للحملان الذكور التوامية في التجارب التثلاث

جدول رقم 9: متوسط وزن الولادة للحملان الذكور التوامية

\begin{tabular}{|c|c|c|c|}
\hline التجربة الثالثة & التجربة الثانية & التجربة الأولى & 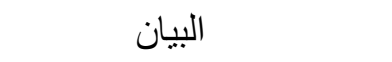 \\
\hline a3,52 & a3,30 & a3,52 & متوسط وزن الو لادة للحملان \\
\hline
\end{tabular}


\begin{tabular}{|l|l|l|l|}
\hline & & & \\
\hline
\end{tabular}

يبين الجدول ( 9) إن متوسط الوزن للحملان الذكور التوأمية بلغ في التجارب

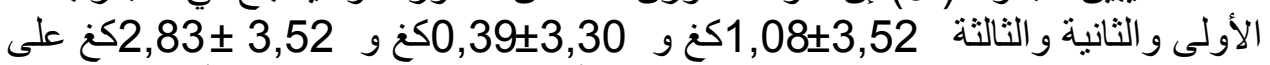

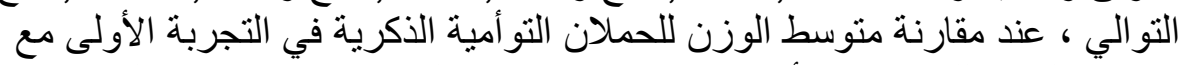

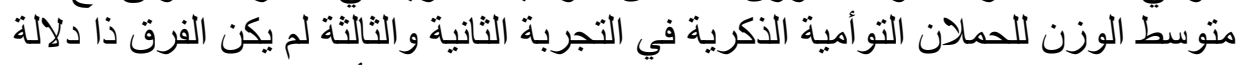

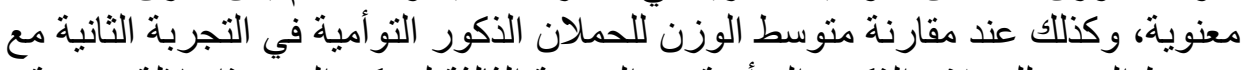

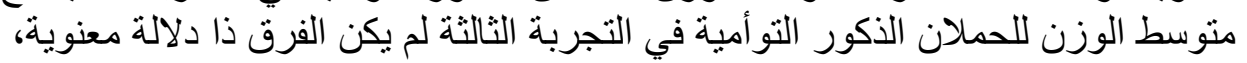

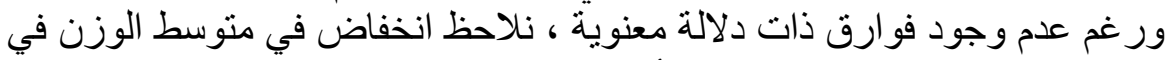

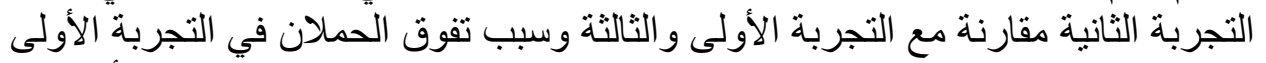

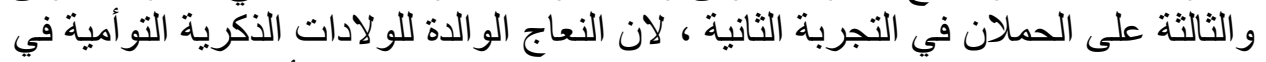

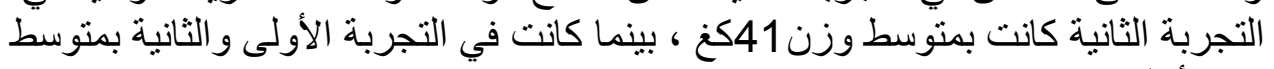
وزن أنقل من 45كغ.

\section{متوسط وزن الولادة للحملان الإناث التوأمية :} الجدول رقم (10) يبين متوسط وزن الإناث التولادة للحملان الإناث التوامية في التجارب الثثلاث

جدول رقم 10: متوسط وزن الو لادة للحملان الإناث التوامية

\begin{tabular}{|c|c|c|c|}
\hline التجربة الثالثة & التجربة الثانية & التجربة الأولى & البيان \\
\hline a3,43 & $\mathrm{b}_{2,99}$ & a3,50 & الإناث التو وزئن كنغ لادة للحملان \\
\hline
\end{tabular}

يبين الجدول (10) إن منوسط الوزن للحملان الإناث النوأمية بلغ في التجارب

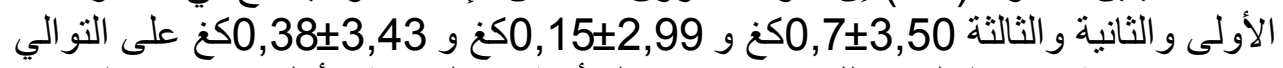

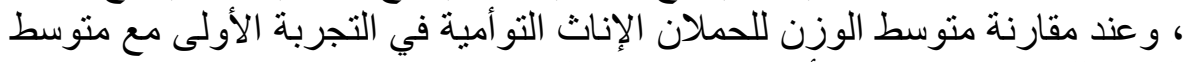

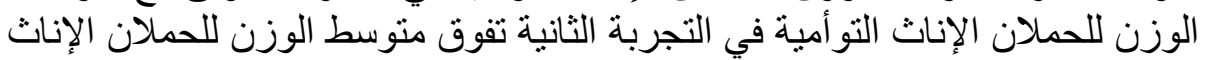

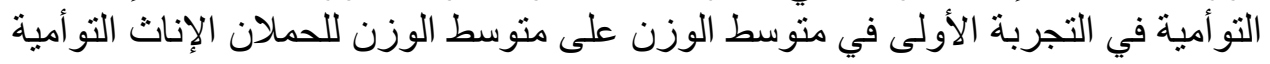

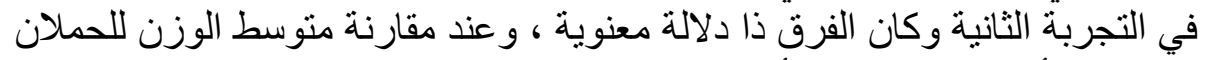

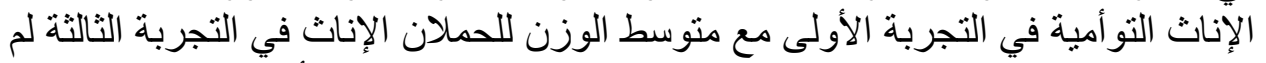

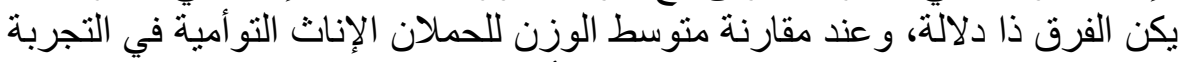

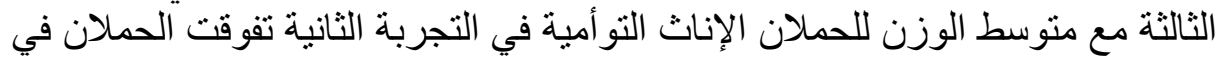

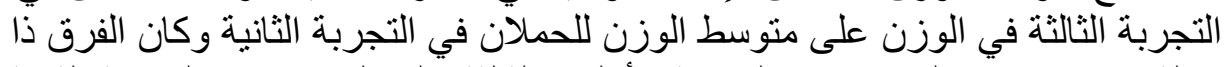

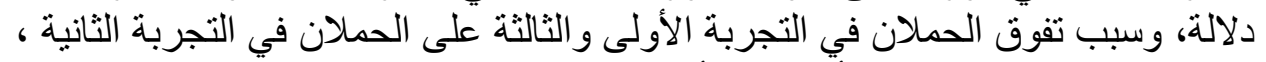

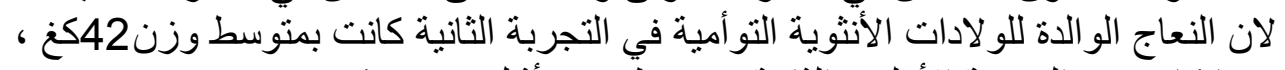

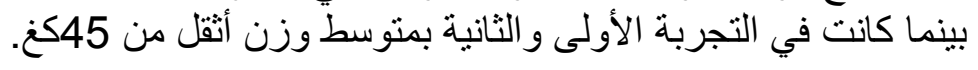
2- متوسطات أوزان الفطام للحملان : 


\section{متوسط وزن القطام للحملان الأكور المفردة :} الجدول (11) يبين متوسط وزن الفطام للحملان الذكور و الإناث في التجارب الثنلاث. الجدول 11: يبين متوسط وزن الفطام للحملان الذكور

\begin{tabular}{|c|c|c|c|}
\hline التجربة الثالثة & التجربة الثانية & التجربة الأولى & البيان \\
\hline a 20,74 & a20,67 & b16,85 & منوسط وزن الفطام للحملان \\
\hline
\end{tabular}

$$
\text { تثبر الأحرف المتثابهة إلى عدم وجود فرق معنوي: (p > 0,05) }
$$

يبين الجدول (11) إن متوسط الوزن للحملان الذكور الفردية بلغ عند الفطام في التجارب

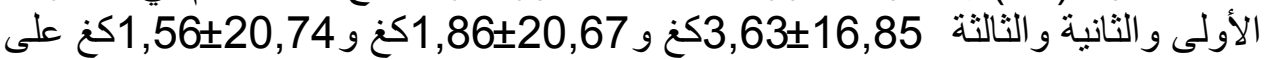

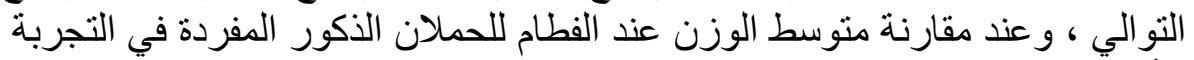

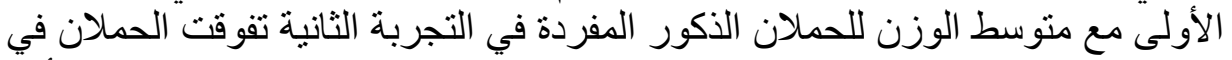

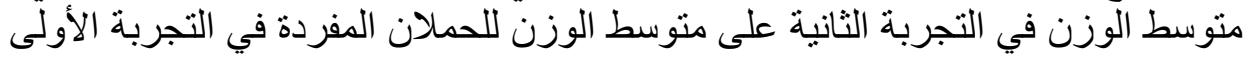

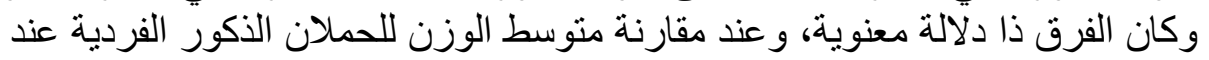

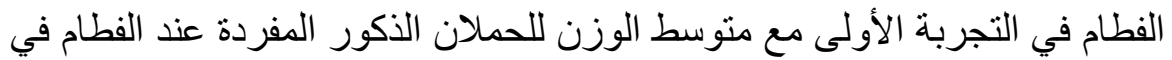

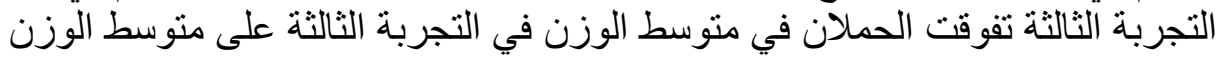

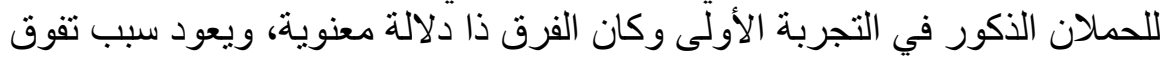

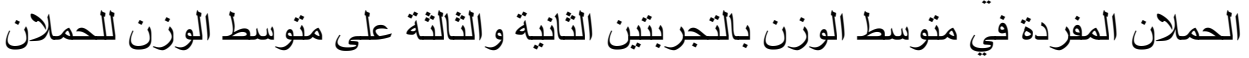

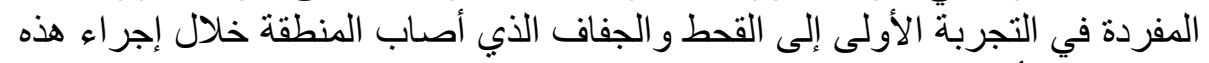

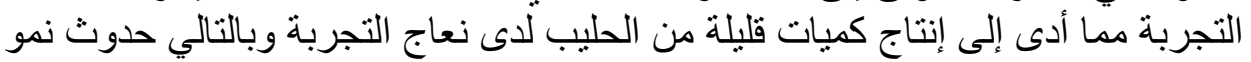

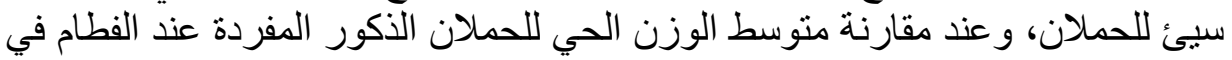

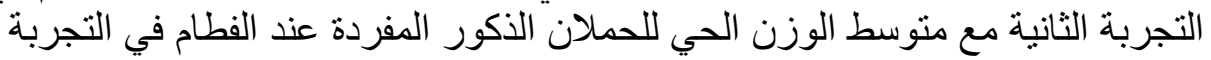
الثالثة لم يكن الفرق ذان دئلانة معنوية.

متوسط وزن الفطام للحملان الإناث المفردة:

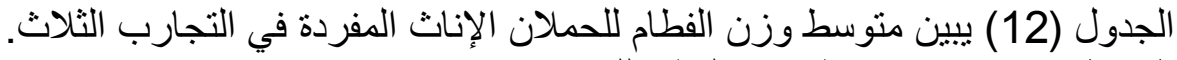
الجدول 12: يبين متوسط وزن الفطام للحملان الإناث الانت الفين

\begin{tabular}{|c|c|c|c|}
\hline التجربة الثالثة & التجربة الثانية & التجربة الأولى & البيان \\
\hline a19,27 & a19,45 & b16,43 & متوسط وزن الفطام للحملان \\
\hline
\end{tabular}

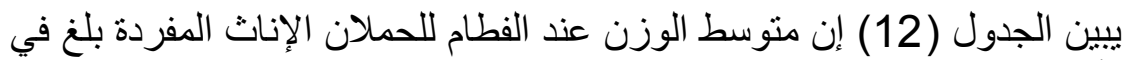

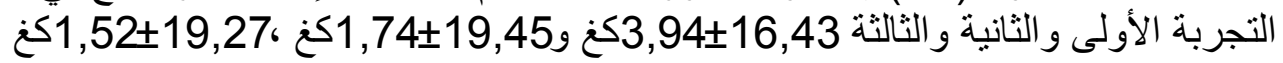
على التوالي ، و عند مقارنة متوسط الوزن للحملان الإناث المفردة عند الفطام في التجربة الأولى مع متوسط التو الوزن للحملان الإناث المفردة عند الفطام في التجربة الثانية فقد تفوق التجان 
منوسط أوزان الحملان الإناث المفردة في التجربة الثانية على متوسط الوز الان للحملان

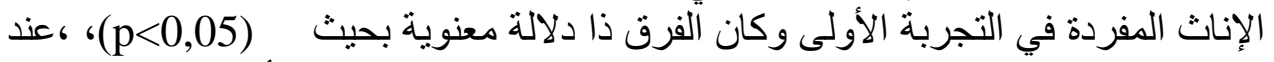

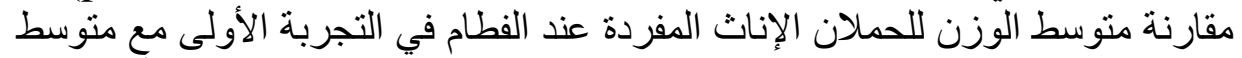

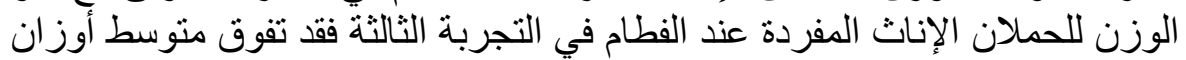

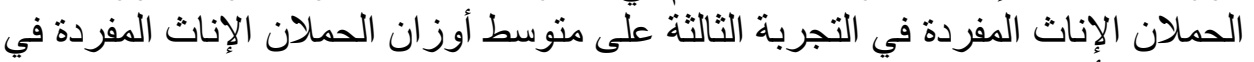

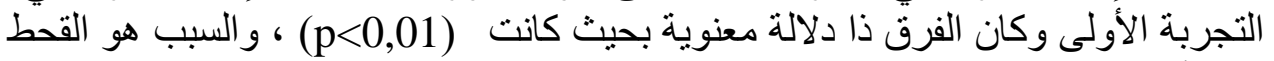

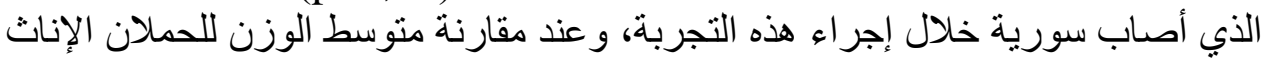

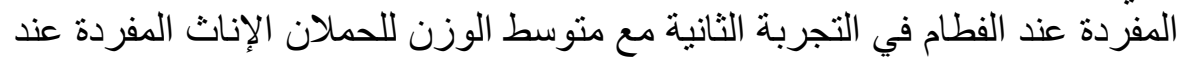
الفطام في التجربة الثالثة لم يكن الفرق ذانة دلانة مثلة معنوية.

متوسط وزن الفطام للحملان الذكور التوأمية :

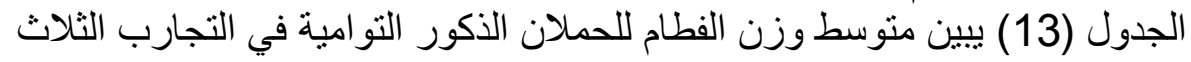
الجدول 13: يبين منوسط وزن الفطام للحملان الذكور التوامية

\begin{tabular}{|c|c|c|c|}
\hline التجربة الثالثة & التجربة الثانية & التجربة الأولى & البيان \\
\hline a15,64 & a 15,23 & b10,49 & الذكور التو ؤمية كنغ الفطام للحملان \\
\hline
\end{tabular}

يبين الجدول (13) إن متوسط الوزن عند الفطام للحملان الذكور التوأمبة بلغ في

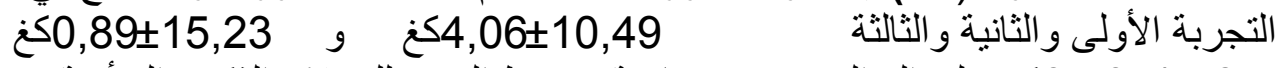

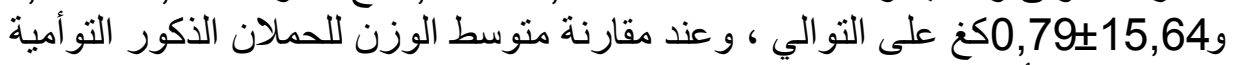

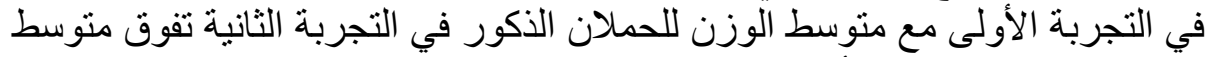

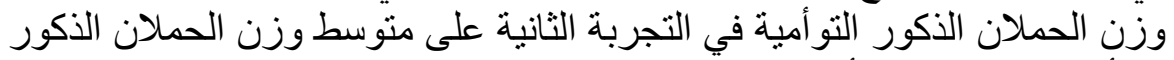

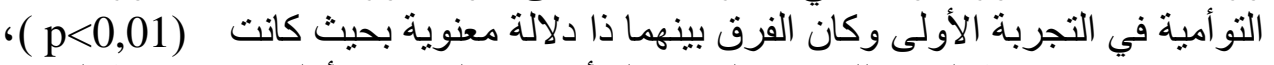

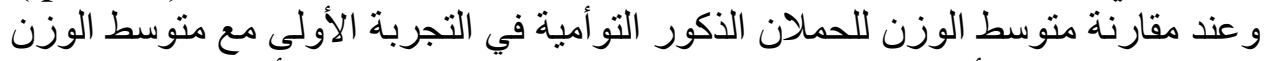

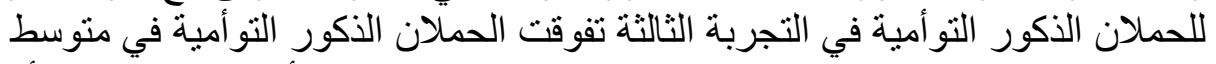

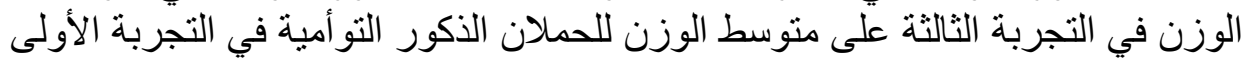

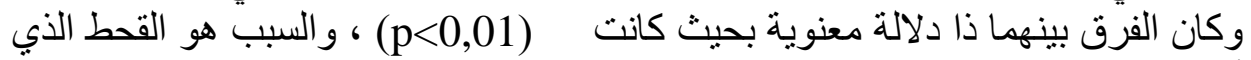

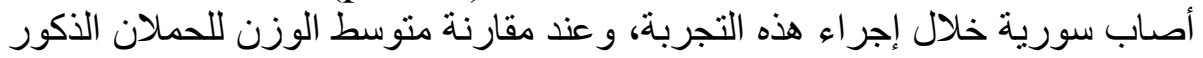

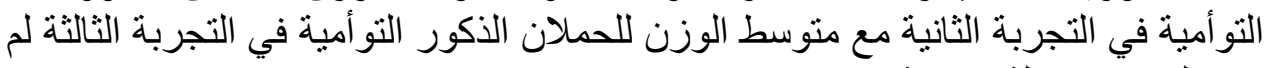
يكن الفرق ذا دلالة معنوية.

متوسط وزن الفطام للحملان الإناث التوأمية: الجدول (14) ييين منوسط وزن الفطام للحملان الإناث التوامية في التجارب الثياث الثلاث الجدول 14: يبين متوسط وزن الفطام للحملان الإناث التو امية 


\begin{tabular}{|c|c|c|c|}
\hline التجربة الثالثة & التجربة الثانية & التجربة الأولى & البيان \\
\hline a15,43 & a14,96 & b12,01 & الإناث التو ؤمية كنغ الفطام للحملان \\
\hline
\end{tabular}

يبين الجدول (14) إن منوسط الوزن عند الفطام للحملان الإناث التو أمية بلغ في التجارب

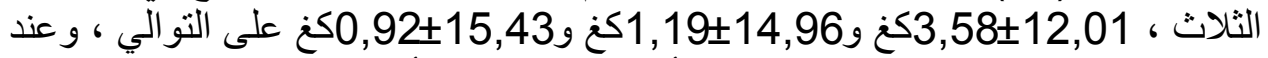

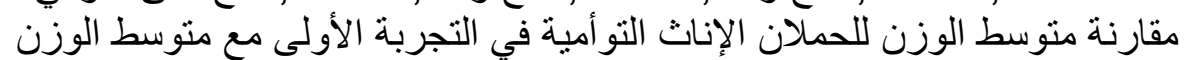

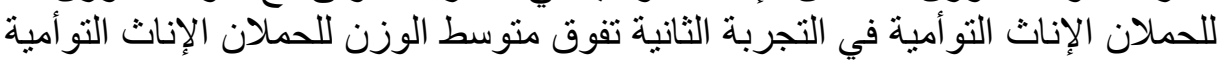

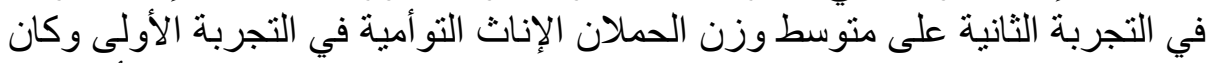

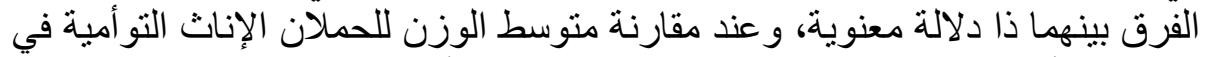

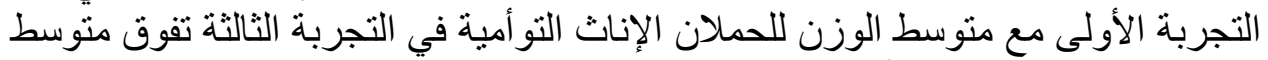

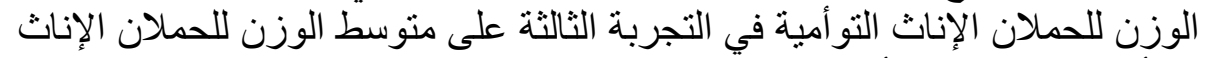

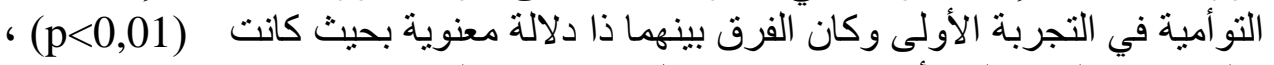

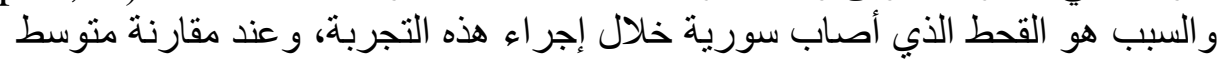

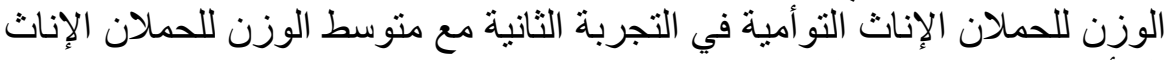

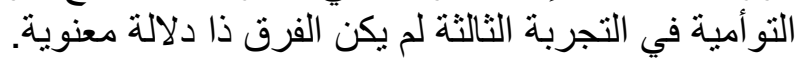

\section{DISCUSSION المناقشة}

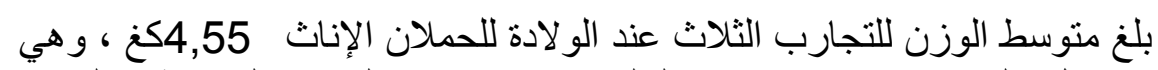

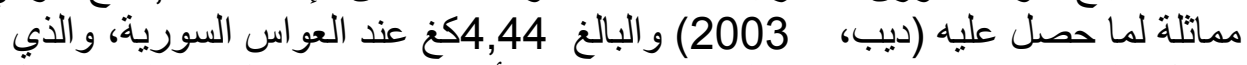

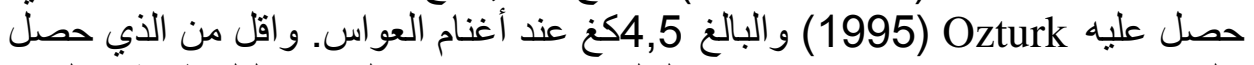
عليه Bahhady واخرون (1995) والبالغ

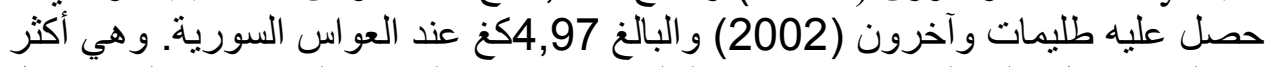

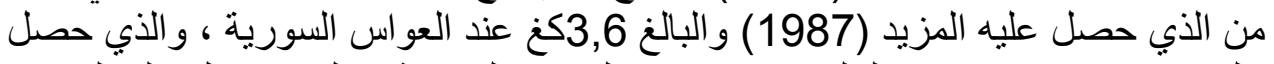

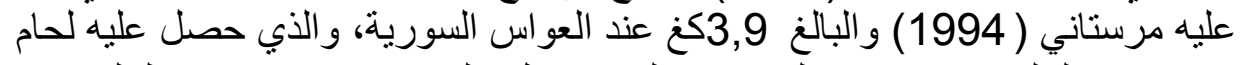

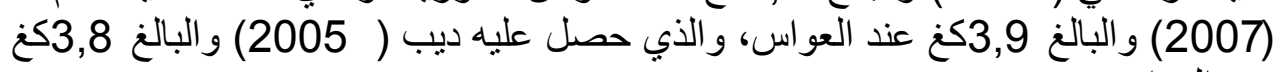
عند العواس.

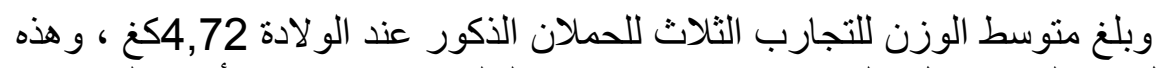

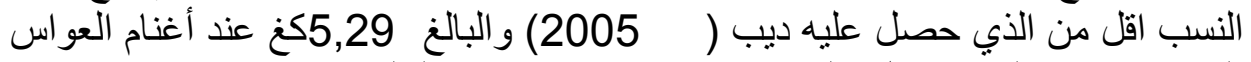

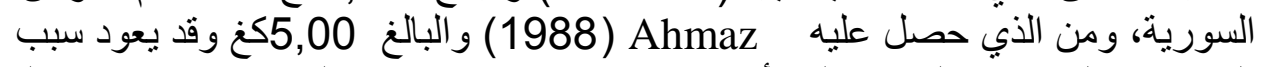

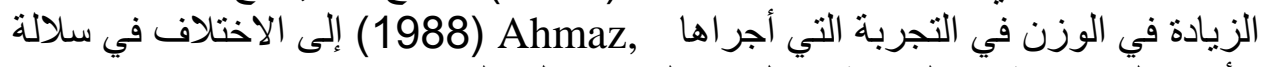

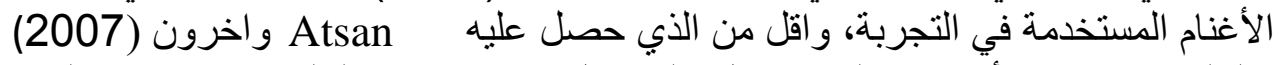
و البالغ 5,00كغ. و أكثر من الذي حصل عليه عدل ( 2003) و البالغ 3,29كغ ، و الذي علي 
حصل عليه سلهب وآخرون ( 1999) و البالغ كغ وكغ والذي حصل عليه مرستاني

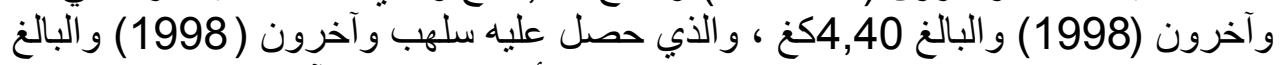
4,30كغ وقد يعود انخفاض الوزن في التجربة التي أجر اها سلهب وآخر وآخرون ( 1998) لأنها أجريت على فطائم العو اس.

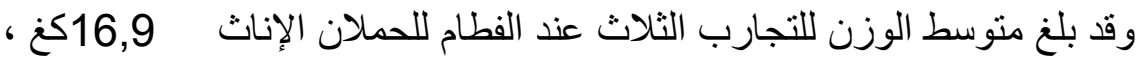

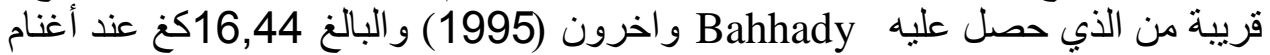

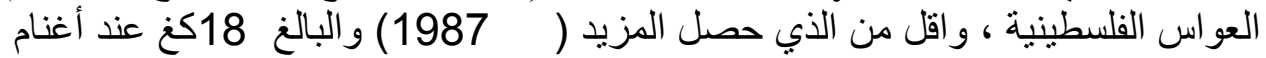

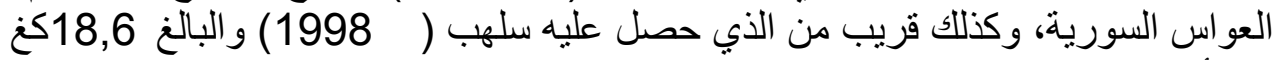

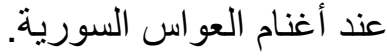

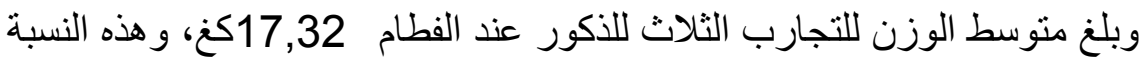

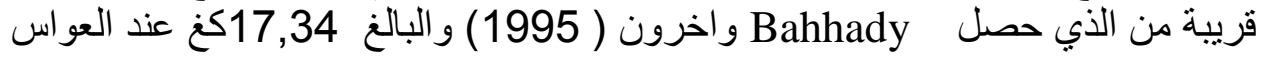

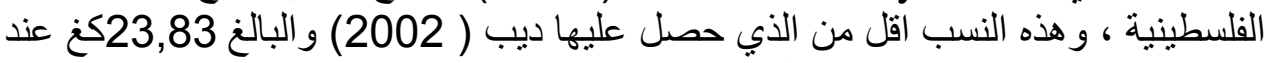

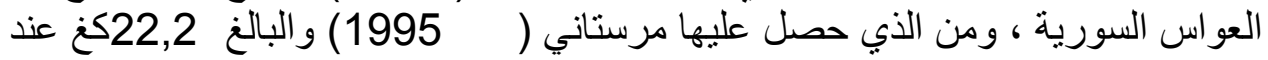

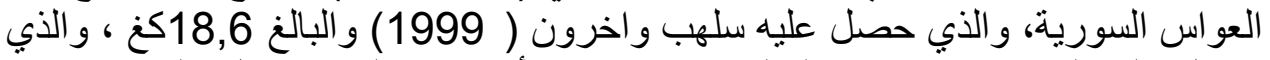

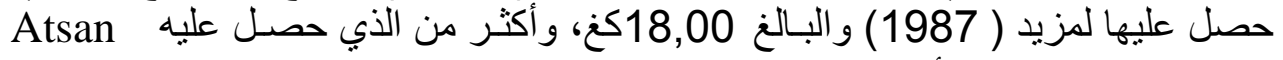

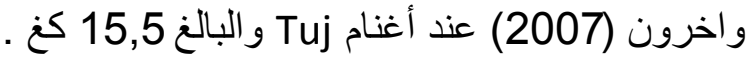

ونلاحظ بأن هنالك انخفاض في متوسط وزن التجارب الثلاث عند الفطام سواء

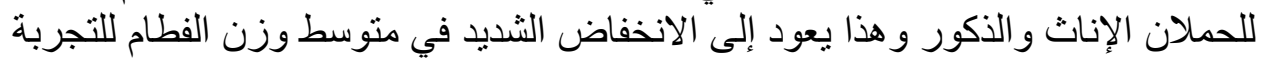

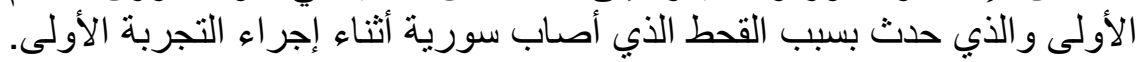

\section{CONCLUSION}

\section{الاستتناج}

يمكن استعمال طريقة الاسفنجات المهبلية عند أغنام العواس وتكثيف الو لادات

داخل وخارج موسم التناسل دون أن يؤثر ذلك على صحة وندة ونمو الحملان.

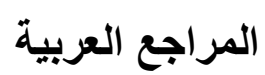

ديب ، علي صالح (2002): تأثثر الفطام المبكر على معدل نمو الحملان و إنتاج الحليب إنها.

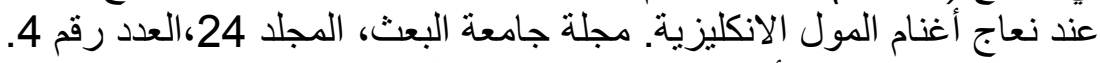

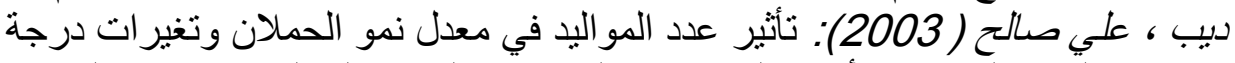

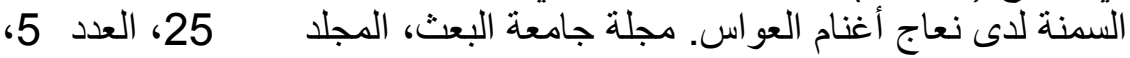

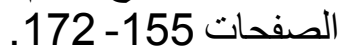




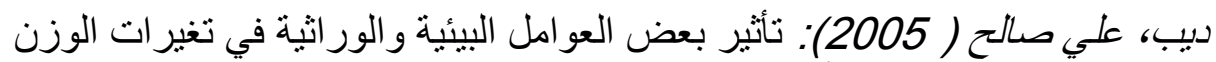

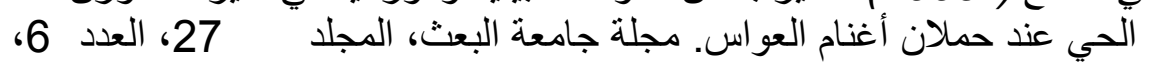
الصفحات 79-79.

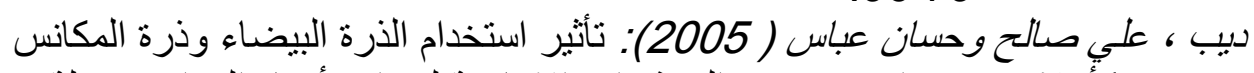

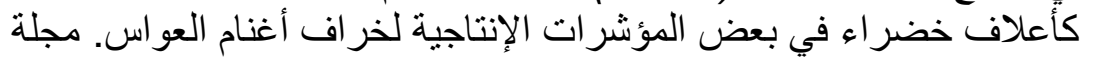

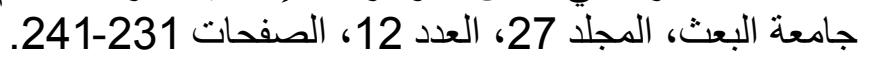

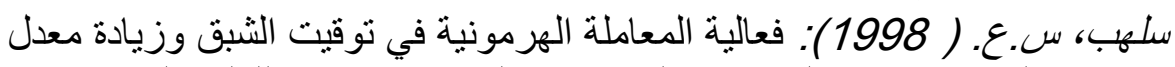

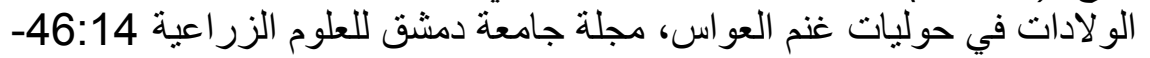

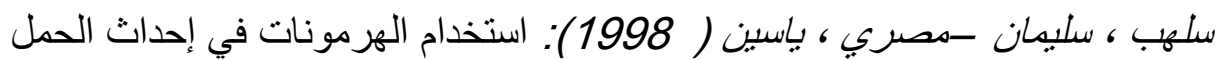

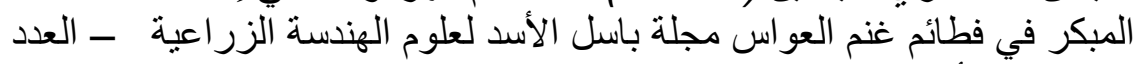

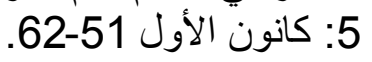

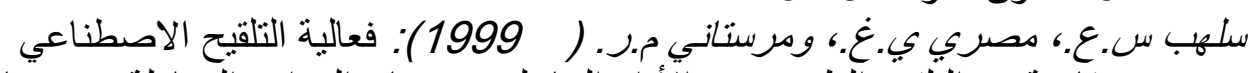

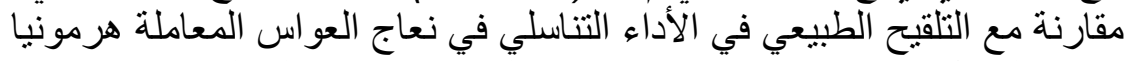

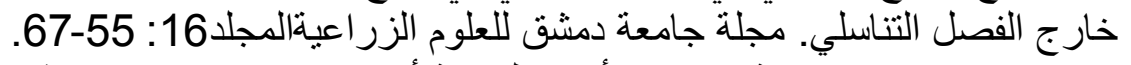

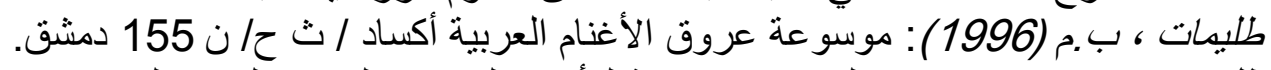

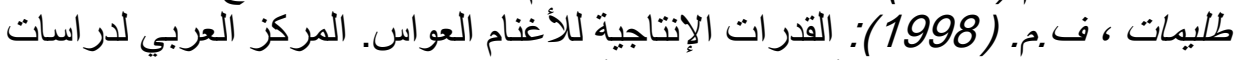

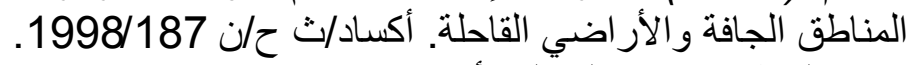

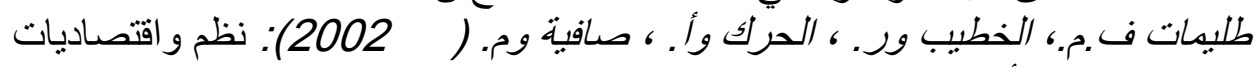

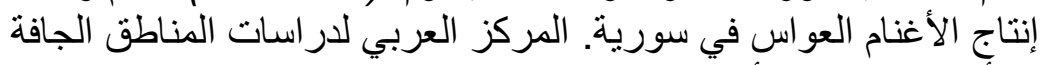

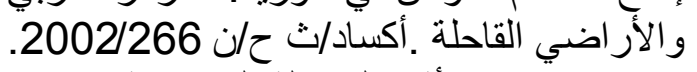

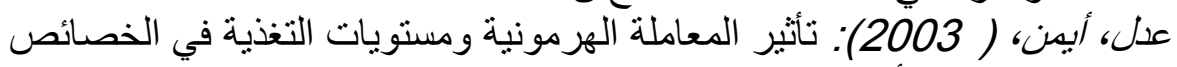

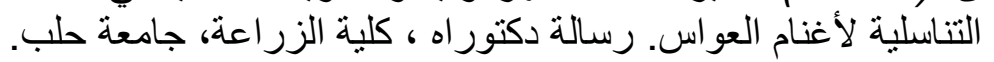

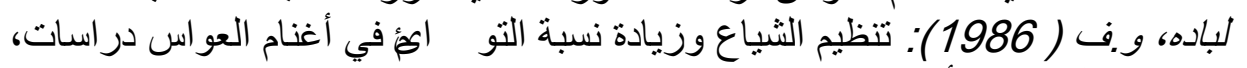

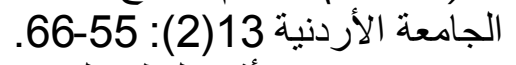

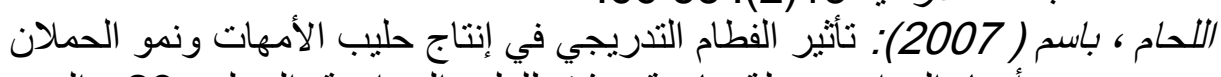

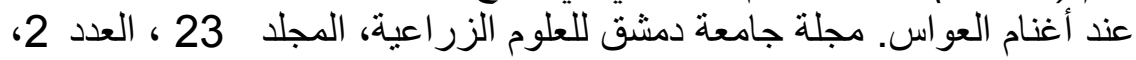

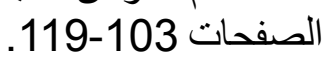

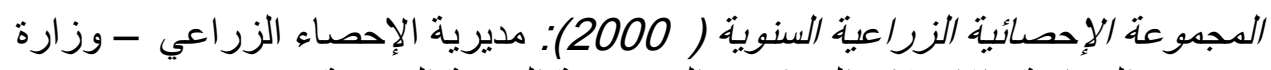

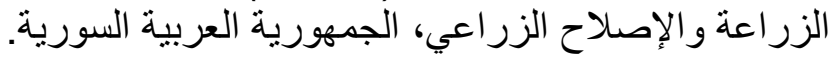

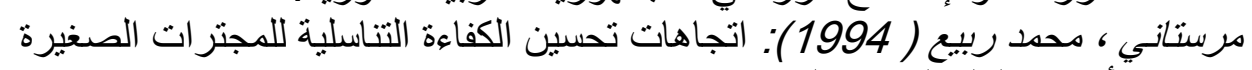

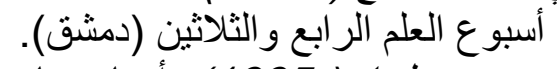
المرستاني، م.ر. ولحام ( 1995): أغنام وماعز (الرنّ) (الر عاية و التتاسل). منشورات جامعة دمشق.

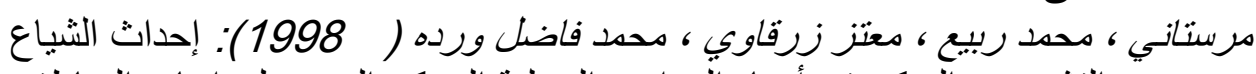
و التشخيص المبكر في أغنام العواسي المحلية.المركز العربي لدراسات المناطق المقات 
الجافة والأر اضي القاحلة (أكساد/ث ح/ن 1948/198)، - هيئة الطاقة الذرية

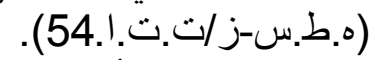
المزيب ، محي (1987): أثر المعاملة بالهرمونات في تحريض الثبق (الوداق) ونسبة

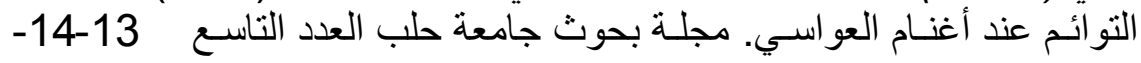
.15

\section{REFERENCES \\ المراجع الأجنبية}

Ahmaz, M. (1988): Assessment of progesterone impregnated intravaginal sponges and gonadotropin treatment on reproductive performance of local sheep breed. American University of Beirut, p. 59.

Atsan, T.; Emsen, E. and Yaprak, M. (2007): An economic assessment of differently managed sheep flocks in eastern Turkey. ITALI. J. Anim. Sct. Vol. 6: 407-141.

Bahhady, F.; Christianen, S.; Harris, H.C. and Thomson, E. (1995): Performance of Awassi lambs grasing common vetch in on- farm and on- station traits. International Center For Agricultural Research in the dry Areas (ICARDA), Syria, pp. 47.

Ozturk, Ayhan, (1995): Repeatability estimates on birth weight and gestation period in Awassi sheep, Ind. Vet. J. 72(10): 1057-1060. 